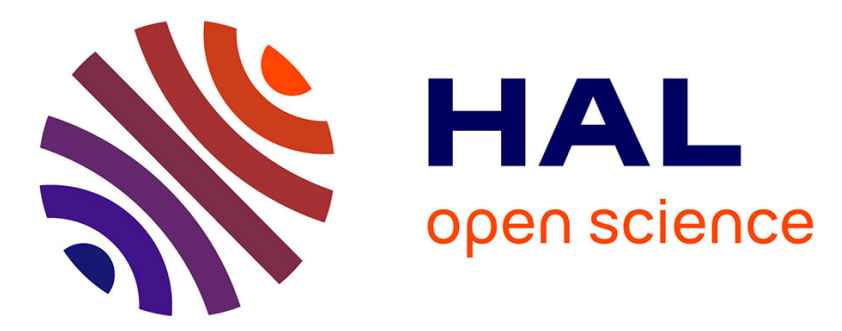

\title{
Carrier confinement and fabrication effects in GaInAs-InP quantum wires and dots
}

\author{
R. Mac Leod, C. Sotomayor Torres, Y. Tang, A. Kohl
}

\section{To cite this version:}

R. Mac Leod, C. Sotomayor Torres, Y. Tang, A. Kohl. Carrier confinement and fabrication effects in GaInAs-InP quantum wires and dots. Journal de Physique IV Proceedings, 1993, 03 (C5), pp.C5335-C5-338. 10.1051/.jp4:1993569 . jpa-00251656

\section{HAL Id: jpa-00251656 https://hal.science/jpa-00251656}

Submitted on 1 Jan 1993

HAL is a multi-disciplinary open access archive for the deposit and dissemination of scientific research documents, whether they are published or not. The documents may come from teaching and research institutions in France or abroad, or from public or private research centers.
L'archive ouverte pluridisciplinaire HAL, est destinée au dépôt et à la diffusion de documents scientifiques de niveau recherche, publiés ou non, émanant des établissements d'enseignement et de recherche français ou étrangers, des laboratoires publics ou privés. 


\title{
Carrier confinement and fabrication effects in GaInAs-InP quantum wires and dots
}

\author{
R.W. MAC LEOD, C.M. SOTOMAYOR TORRES, Y.S. TANG and A. KOHL*
}

Nanoelectronics Research Centre, Department of Electronics and Electrical Engineering, University of Glasgow, Glasgow G12 8QQ, England

* Institut für Halbleiter Technik der RWTH, Walter-Schottky-Haus, Sommerfeldstrasse, 5100 Aachen, Germany

\begin{abstract}
We report a fabrication and luminescence study of GaInAs-InP single quantum wells down to lateral dimensions of $15 \mathrm{~nm}$. The changes in the energy position of the spectrum of wires and dots is explored as a function of processing parameters. Blue energy shifts of up to $8 \mathrm{meV}$ observed are too small considering the lateral dimensions and therefore processing induced strain has to be invoked to understand the weaker confinement in these structures. Tests of wet etching and annealing are reported.
\end{abstract}

There have been several reports on quantum wires and dots fabricated in lattice-matched GaInAsInP quantum wells[1-9]. The most striking feature has been the wide spread of reported confinement energies which, for example, for $40 \mathrm{~nm}$ wide wires spans the range from $0-11 \mathrm{meV}$.

The aim of this work was to fabricate the smallest possible wires and dots by electron - beam lithography and reactive ion etching and to inspect the luminescence of these nanostructures particularly before and after a given processing step to gain an insight into the contributions to the final blue energy shift.

Several samples were used in this work, however the results presented here are from one sample grown by MOCV D on a semi-insulating InP substrate. It consisted of a $200 \mathrm{~nm}$ InP buffer layer, a $7 \mathrm{~nm}$ GaInAs quantum well and a $12 \mathrm{~nm}$ InP top barrier. The fabrication process employed a Leica-Cambridge EBPG HR5 Beamwriter working at $50 \mathrm{KeV}$. The exposure used varied from $36 \mu \mathrm{C} / \mathrm{cm}^{-2}$ for the $15 \mathrm{~nm}$ diameter dots, through $700 \mu \mathrm{Ccm}^{-2}$ for $25 \mathrm{~nm}$ wide wires to $1960 \mu \mathrm{C} / \mathrm{cm}^{-2}$ for high resolution $25 \mathrm{~nm}$ diameter dots. The bilayer resist used was $2.5 \%$ $\mathrm{BDH}$ and $2.5 \%$ Elvacite. Then a layer of $\mathrm{SrF}_{2} / \mathrm{AlF}_{3}$ approximately $25 \mathrm{~nm}$ thick was evaporated and liftedoff. The samples were reactive ion etched in $\mathrm{CH}_{4} / \mathrm{H}_{2}$ in a gas flow rate of 1 to 2 , an etch pressure 30 $\mathrm{mTorr}$ at a rate of $31 \mathrm{~nm} / \mathrm{min}$. The luminescence measurements were recorded in a standard system, using the $488 \mathrm{~nm}$ line of an Argon laser exciting both the InP and GaInAs layers, a Ge detector and sample temperatures between 4 and $300 \mathrm{~K}$ The luminescence of the control sample is shown in Fig.1. Variations across the sample size to be patterned were within $4 \mathrm{meV}$ in the energy position of the quantum well emission.

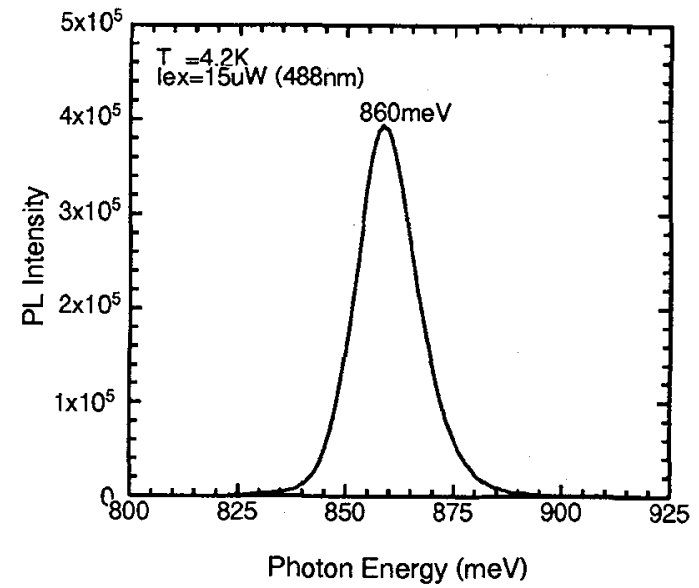

Fig.1 4K Luminescence from as-grown sample. 
The emission from dots as a function of dot diameter is shown in Fig. 2. The magnitude of the blue shift for a given lateral size is smaller than expected from rough calculations of exciton confinement in a GaInAs-InP wire with infinite walls. It is clear from this figure that there are other mechanisms giving rise to energy shifts of the emission from the quantum dots. There are several possible candidates including alloy fluctuations, impurities and or defects introduced during the etching process, quantum well thickness variations and strain in the etched structures. Concerning the localization related possibilities we compared the integrated luminescence emission from wires of the same width as a function of wire length. It is know from our work in high quality GaAs-GaAlAs wires [10] that with a random distribution of impurities in the quantum well material, the normalized integrated intensity of wires of decreasing lenght increases since statistically there is a smaller probability of shorter wires having a non-radiative exciton trap. Fig. 3 shows the integrated emission intensity against wire length for GaInAs-InP 100nm wide wires. The trend shown is opposite to that in GaAs-GaAlAs wires suggesting that exciton diffusion hardly occurs and therefore the emission observed from wires and dots in our material comes from localized excitons. This was further demonstrated by both power and temperature dependence of the emission line from the control sample: The integrated emission intensity followed a linear dependence on power over four decades confirming the emission originated from the fundamental tmasition in the quantum well. The temperature dependence of the emission energy followed the band edge of GaInAs and was sucessfully fitted with the expression $\mathrm{E}_{\mathrm{O}}(\mathrm{T})=\mathrm{E}_{\mathrm{O}}(0)+\alpha \mathrm{T}^{2} /(\mathrm{T}+\beta)$, with $\mathrm{E}_{\mathrm{O}}$ (0) $=0.862 \mathrm{eV}, \alpha=2.7 \times 10^{-4} \mathrm{eV} / \mathrm{K}$ and $\beta=127$

$\mathrm{K}$ the temperature coefficient $\alpha$ compares well with those of GaAs, InP and InAs. Moreover, the temperature dependence of the full width at half maximum (FWHM) of the control sample (quantum well) emission exhibited a reduction from 14.2 to $12.3 \mathrm{meV}$ when the temperature was raised from 4 to approximately $20 \mathrm{~K}$ and then it increased again to a maximum value of $25 \mathrm{meV}$ at $100 \mathrm{~K}$ reamining in the range of $21-25 \mathrm{meV}$ up to room temperature. This is shown in Fig. 4 opposite. This indicates that the broadening mechanisms responsible for the FWHM are very complex. At least four mechanisms are important here: impurity broadening, alloy disorder broadening, thermal broadening and electronphonon interaction. Further work is in progress to quantify these contributions.

The effect of processing in the wire and dots luminescence spectrum was also studied. The reactive ion etching processes is known to create defects at least on the surface of the etched

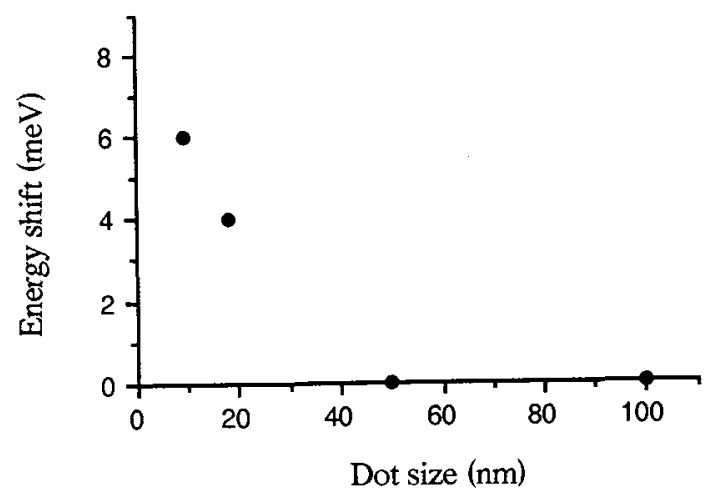

Fig.2 Energy shift of $5 \mathrm{~K}$ emission from dots against dot diameter.

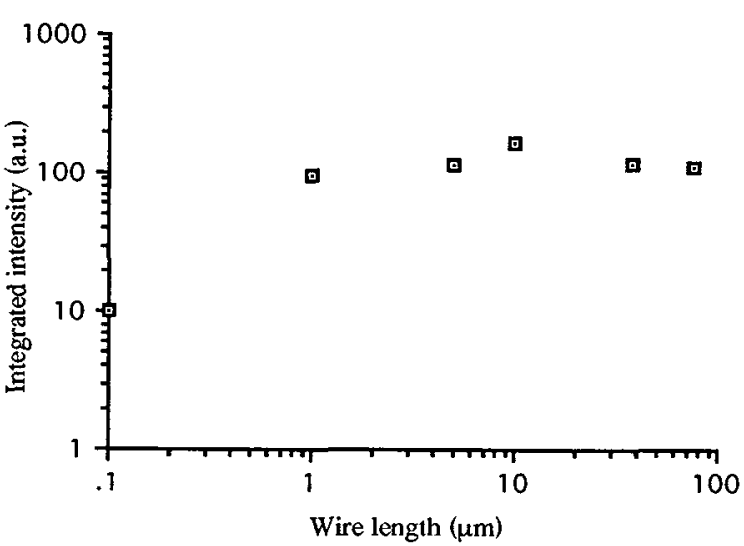

Fig. $35 \mathrm{~K}$ Integrated emission intensity from $100 \mathrm{~nm}$ wide wires against wire length.

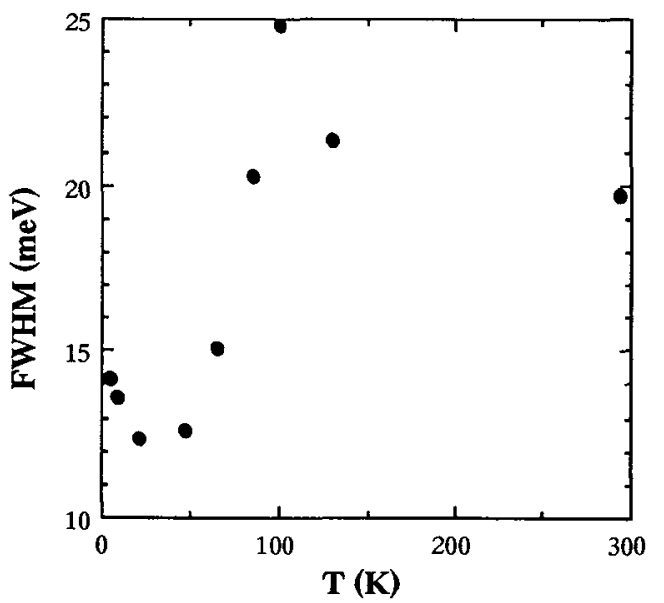

Fig.4 Temperature dependence of the FWHM of control sample emission. 

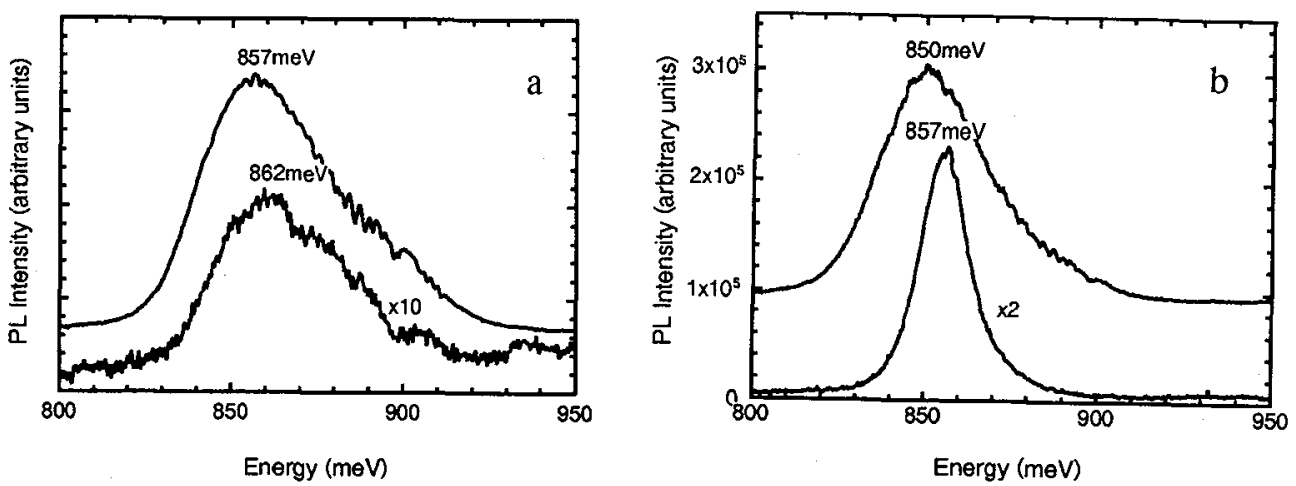

Fig. 5 Emission from wires before (top spectra) and after (bottom spectra) annealing. (a) $20 \mathrm{~nm}$ wires and (b) $50 \mathrm{~nm}$ wires.

structures. An annealing step was carried out in two wire arrays under the following conditions: temperature $=400 \mathrm{C}$, annealing time $=2$ minutes, gaseous environment $=95 \% \mathrm{Ar}+5 \% \mathrm{H} 2$. The luminescence spectrum before and after annealing are shown in Figs. $5 \mathrm{a}$ and $5 \mathrm{~b}$ for the 20 and $50 \mathrm{~nm}$ wide wire arrays, respectively. In the case of the narrower wires the emission intensity decreased dramatically after annealing and the centre of the emission was shifted to higher energies by about $6 \mathrm{meV}$. In the case of the $50 \mathrm{~nm}$ wide wires the emission became significantly narrower, dropping in intensity by a factor of two and also shifting to higher energies by $7 \mathrm{meV}$.

In an attempt to remove physically the 'damaged' surface layer several annealed arrays were wet etched in $4 \mathrm{ml} \mathrm{HCl}: 4 \mathrm{ml} \mathrm{H} 2 \mathrm{O}_{2}: 4 \mathrm{ml}$ $\mathrm{CH}_{3} \mathrm{COOH}$. Fig. 6 shown the emission of an array of $30 \mathrm{~nm}$ diameter dots and a control area (mesa) after annealing and wet etching. With respect to the control mesa the dot luminescence peak is broader and shifted to higher energies by almost $12 \mathrm{meV}$ with somewhat stronger intensity.

In as-grown samples with the largest FWHM in the quantum well emission spectrum, the wire and dot luminescence showed a broad high energy band above the heavy-hole1- electron 1 transition. This high energy emission subsequently disappeared after wet etching suggesting that contribution to this high energy emission may have its origin in surface states created during the fabrication and the associated band-bending and not in hot luminescence due to the intrinsic 'bottleneck' effect [11].

Bypassing the annealing step, a fresh piece of the sample was processes in the usual way to fabricate $20 \mathrm{~nm}$ diameter dots and immediately after reactive ion etching it was subjected to wet etching in the solution mentioned above. Spectra of the dot array and of the control mesa are shown in Fig. 7. Compared to the control mesa the emission from dots became weaker, broader, although it was not as broad as the emission from the dry etched-only samples, and appeared blue shifted by $4 \mathrm{meV}$.

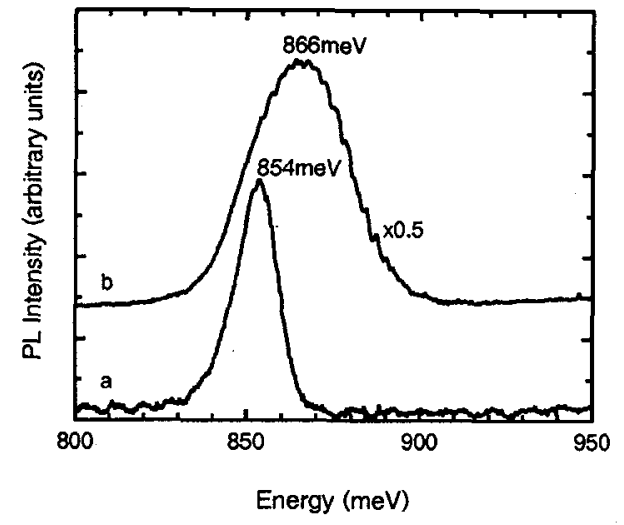

Fig.6 Emission from a control mesa (a) and $30 \mathrm{~nm}$ dots (b) after dry etching, annealing and wet etching. (n)

西

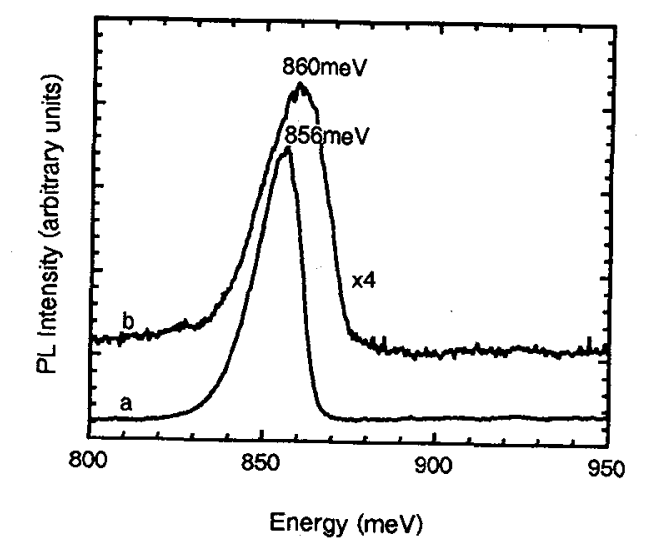

Fig.7 Emission from a control mesa (a) and $20 \mathrm{~nm}$ dots (b) after dry etching and wet etching. 


\section{Conclusions}

This study strongly suggests that the origin of the energy blue shift in GaInAs wires and dots results from a combination of factors which may include: strain, extrinsic centres, exciton confinement, etc and highlights the need to determine the role of these mechanisms and a way to control them.

Concerning further processing induced effects, annealing and wet etching and wet etching without annealing of the samples produced different emission peak energies at higher energies than the $2 \mathrm{D}$ control sample. The integrated intensity also varied in wires and dots by up to a factor of 10 . The energy shifts arising from processing stepts are similar to those measured as a function of decreasing lateral size.

There is a clear need to model these structures considering the factors mentioned above and quantify them in order to understand the nature of the actual confinement. The very small sizes achieved suggest that these observations may also be relvant to directly-grown wires and dots

\section{References}

[1] Notomi M., Naganuma M., Nishida T., Tamamura T., Iwamura H., Nojima S. and Okamoto M. Appl. Phys. Lett. 58 (1991) $720-722$

[2] Patillon J. N., Jay C., Iost M., Gamonal R., André J., Soucail B., Delalande C and Voos M. Superlattices and Microstructures 8 (1990) 335 - 339

[3] Samuelson L., Georgsson K., Gustafsson A., Maximov I., Montelius L., Nilsson S., Seifert W. and Semu A., Proc. SPIE Symp. Compound Semiconductor Physics and Devices vol 1676 (1992) 154-160

[4] Temkin H., Dolan G. J., Panish M. B. and Chu S. N. G., Appl. Phys. Lett. 50 (1987) 413-415

[5] Naganuma M., Notomi M., Iwamura H., Okamoto M., Nishida T. and Tamamura T., J. Crystal Growth 105 (1990) 254-259

[6] Adesida I., Chang H., Ballegeer D., Liu X., Bishop S., Caneau C. and Bhat R., Proc. SPIE Symp Compound Semiconductors Physics and Devices, vol 1676 (1992)

[7] Miller B. I., Shakar A., Koren U. and Corvini P., Appl Phys. Lett. 54 (1989) 188-190

[8] Gershoni D., Temkin H., Dolan G. J., Dunsmuir J., Chu S. N. G. and Panish M. B., Appl. Phys. Lett. 53 (1988) 995-997

[9] Izrael A., Marzin J.-Y., Sermage B., Birotheau L., Robein D., Azouley R., Benchimol J. L., Henry L., Thierry-Mieg V., Vagan F. R. and Taylor L., Jap. J. Appl. Phys. 30 (1991) 3256-2885

[10] Leitch W. E., Sotomayor Torres C. M., Lootens D., Thoms S., Van Daele P., Stanley C. R., Demeester P. and Beaumont S. P., Surface Science 263, (1992) 622-627

[11] Benisty H., Sotomayor Torres C. M. and Weisbuch C., Phys. Rev. B 44 (1991) 10945-10948 